\title{
An Investigation into the Prevalence of Migraine and its Prophylactic Treatment Patterns in the Czech Republic
}

\section{David Dolezil}

Prague Headache Center, DADO Medical s.r.o.

\section{Jolana Markova}

University Thomayer Hospital, Prague

Jiri Klimes ( $\square$ jiri.klimes@novartis.com )

Novartis s.r.o., Prague

\section{Zuzana Pocikova}

Novartis s.r.o., Prague

\section{Filip Dostal}

Novartis s.r.o., Prague

\section{Radka Stepanova}

Aixial s.r.o., Brno

Adam Svobodnik

Aixial s.r.o., Prague

\section{Research article}

Keywords: Migraine, Prevalence, CGRP, Prophylactics, Triptans, Czech Republic, Claims database

Posted Date: June 8th, 2020

DOl: https://doi.org/10.21203/rs.3.rs-33287/v1

License: (c) (1) This work is licensed under a Creative Commons Attribution 4.0 International License. Read Full License 


\section{Abstract}

Background A national primary and secondary healthcare-level study in the Czech Republic has not yet been conducted to evaluate the prevalence of migraine. Considering the success of newly developed calcitonin gene-related peptide (CGRP) pathway-targeted therapies, we analyzed the current treatment patterns (acute and prophylactic) in migraine patients and the number of migraine patients potentially eligible for treatment with these therapies.

Methods This retrospective study utilized the Ministry of the Interior Health Insurance Fund claims database of the Czech Republic wherein every citizen is insured, according to local regulations. Migraine patients with or without aura, and potentially on triptan therapy, from 2012-2016, were included in this study. The prevalence approach (index years 2012-2016) included all patients present in each index year. Prophylactic therapies were followed for three and seven years prior to the index year, including the index year, until 2010. The incidence approach (index years 2012-2016) included all patients first diagnosed in each index year. Prophylactic therapies were followed for the next three years, including the index year, until 2017 following incidence approach. The primary endpoint of this study was to determine the rate of migraine prevalence and diagnosis for each index year during the period 20122-2016. The study also evaluated prophylactic and acute treatment patterns and comorbidities among patients in 2016.

Results The rate of migraine prevalence was $1 \%$ and the rate of diagnosis was $0.2 \%-0.4 \%$. The prevalence of migraine in adults and females was similar to global prevalence. By prevalence approach, approximately $39 \%$ of the patients were on prophylactics, and $11.2 \%$ and $21.6 \%$ of the patient population had two prior treatment failures (three- and seven-year recall period, respectively). Overall, antiepileptics $(26 \%)$ and beta blockers (15.8\%) were the most prescribed prophylactics, and sumatriptan was the predominant triptan used (12\%) for acute treatment.

Conclusion Taking into account the number of inhabitants in the Czech Republic (10.7 million), there could be up to 23,000 adult patients eligible for novel CGRP therapies.

\section{Background}

According to the Global Burden of Disease study, neurological disorders are the leading cause of disability-adjusted life years (DALY) and the second leading cause of death [1]. Stroke (42.2\%), migraine (16.3\%), Alzheimer's and other dementias (10.4\%), and meningitis (7.9\%) were the top disorders contributing to the cause of neurological DALYs [1]. In terms of years lived with disability (YLD), migraine is ranked second globally and has a prevalence of $14.4 \%$, with 1.04 billion living with migraine and 45.1 million YLDs [2]. Despite being one of the most frequent neurological disorders, the burden of this affliction is highly underestimated [3].

Treatment of chronic and episodic migraine (CM and EM) involves abortive or acute treatment and preventive or prophylactic treatment [4]. Triptans are the first-line of treatment for acute migraine and although they may be effective in treating acute attacks, frequent use may lead to medication overuse 
and medication overuse headache [5]. It is thus recommended that prophylactic therapy be used to limit the frequency of acute therapy [6]. A number of prophylactic drugs to treat migraine, such as antidepressants, antihypertensives (beta blockers, angiotensin receptor blockers, angiotensin-converting enzyme inhibitors) and antiepileptics were initially developed for other indications and were not intended for treatment of migraine [6, 7]. In recent years, treatments specific for migraine have been developed, targeting the calcitonin gene-related peptide (CGRP) pathway, which has been known to play a central role in migraine pathophysiology [8]. One of these therapies is erenumab, a fully human monoclonal antibody that blocks CGRP activity by targeting the CGRP receptor. In clinical trials conducted in patients with $\mathrm{EM}$ and $\mathrm{CM}$, erenumab has demonstrated its efficacy by reducing monthly migraine days and was welltolerated with an adverse event profile similar to placebo $[9,10]$. Another area of consideration when treating migraine patients is comorbidities. Conditions such as cardiac diseases, psychiatric diseases, obesity and epilepsy are some of the commonly occurring comorbidities in patients already suffering from migraine [11]. Thus, it is particularly important to contextualize all of the medical conditions of a migraine patient in order to effectively manage the condition.

Over the years, cross-sectional studies such as the International Burden of Migraine Study and the Eurolight project have been conducted across various European countries to collect migraine prevalence data $[12,13]$. Studies have also compared the clinical and economic burden of migraine in 31 countries across the world using self-reported data from online bulletin boards [14]. Considering the results of the global burden of disease study (2018), with burgeoning number of migraine patients across the world [2], it is imperative that we study a country's treatment patterns and individual drug usage in a proper healthcare management setting in order to improve healthcare delivery. In the Czech Republic, no realworld national study evaluating the prevalence or diagnosis of migraine and its treatment patterns has been conducted at primary and secondary care levels. A recent study in the country analyzed the burden of migraine using data from a self-reported smartphone application [15], but self-reported migraine may or may not have been confirmed by a medical diagnosis and thus, any data obtained at a local or national level are not entirely reliable. Claims data are being increasingly used in medical research as a source of useful information $[16,17]$ because they record details on diagnosis, treatments provided, care providers, billed and reimbursed amounts, and show concordance with patient self-reports/electronic health records with acceptable accuracy $[16,18]$.

The present study collected and analyzed real-world claims data from ZP MV (Ministry of the Interior Health Insurance Fund) in the Czech Republic. This study could inform the use of novel CGRP therapies and their upcoming launches with respect to a proper setting of migraine disease management and budgeting. The current article focuses to present the observations from this study.

\section{Methods}

\section{Type of Study and Study Population}


This was an observational, retrospective study utilizing the ZP MV claims database (approximately $12 \%$ of the whole Czech Republic population). It is to be noted that all the citizens of the Czech Republic (10.7 million) [19] are insured, by law. Three migraine populations were included in this study: (a) pure migraine population with or without aura (Population A), (b) potential migraine population on triptan therapy (Population B), and (c) total migraine population, i.e. Population A + Population B (Population C). All primary and secondary endpoints were analyzed separately for the three population subgroups. Data for Population $\mathrm{C}$, which includes the complete migraine population, including those on triptan therapy, are presented in this article.

\section{Study Design}

This study focused on two approaches:

1. Prevalence approach - included all patients of the study cohort present in each year (already existing and newly diagnosed) within the period 2012-2016. Prophylactic therapies were followed for three and seven years prior to the reference year, including the reference year, e.g. for the reference year 2016, prophylactic therapies were followed up for 2016 and back to 2014 (three-year recall period), and for 2016 and back to 2010 (seven-year recall period) (Figure 1 a).

2. Incidence approach - included all patients of the study cohort first diagnosed in each year during the period 2012-2016 (newly diagnosed patients, i.e. patients not having any migraine claims data before the reference year). Prophylactic therapies were followed up for the subsequent years, including the reference year, e.g. for the reference year 2015, prophylactic therapies were followed up for 2015, 2016 and 2017 (Figure 1b). This approach provides a clearer picture of prophylactic treatments in terms of sequences used because the prevalence/cross-sectional approach does not capture the patients independently when they initiate their prophylactic treatment. All descriptive analyses were performed within the index/reference year, except for the prophylactics, which were also observed beyond the index/reference year.

In this manuscript, primary endpoint included data for all the years from 2012 to 2016 . Demographic characteristics of the patient population and the data for secondary endpoints were presented for the index year 2016.

\section{Primary Endpoint}

The primary endpoint was the prevalence and diagnosis rate of migraine for each reference/index year within the time period 2012-2016, using the prevalence and incidence approaches, respectively. According to the prevalent analysis approach, each patient having migraine-related medical procedures and/or prophylactic or acute medication recorded within the time period 2012-2016 was counted into the prevalence of migraine for the corresponding index year. According to the incident analysis approach, each patient having migraine-related medical procedures and/or prophylactic or acute medication 
recorded within the time period 2012-2016 was counted into the incidence of migraine for the corresponding index year unless any migraine-related medical procedures were present prior to the index year. This rate was evaluated for the corresponding index year based on the type of analysis approach and was presented as the number and percentage of migraine patients out of the total insured population.

\section{Secondary Endpoints}

\section{Prophylactic treatment}

- Number of migraine patients treated with a particular number of prophylactic medications $(0$, $\geq 1, \geq 2, \geq 3$, and $\geq 4$; cumulative prophylactic line, i.e. 0 prophylactic medications used, $1^{\text {st }}$ and subsequent prophylactic line, $2^{\text {nd }}$ and subsequent prophylactic line, and so on) in the index year 2016, with three- and seven-year recall periods.

- Proportion of each prophylactic medication used in the index year 2016 (both the therapeutic subgroup and individual drugs; no prophylactic lines), with a three-year recall period.

Acute treatment - Number of daily doses of triptan and the types of triptan (triptans were the only acute treatment form recorded) with respect to the number of concomitant prophylactic medications used $(0$, $1^{\text {st }}, 2^{\text {nd }}, 3^{\text {rd }}, 4^{\text {th }}$; distinctive prophylactic line or exact number of concomitant prophylactic medications used) in the index year 2016.

Comorbidities -Number of migraine patients with comorbidities, and the number and types of comorbidities in the index year 2016.

\section{Ethics Approval}

This was a retrospective, anonymized study requiring no approval from the ethics committee or health authorities, or informed consent from patients. No personal data were used in the study. Data used in this study were from a pre-existing database.

\section{Statistical Analysis}

The data obtained from the study population were analyzed using descriptive statistics. Categorical data are summarized as an absolute or relative frequency. Continuous data are presented as the number of available observations, means and standard deviations (SD). Percentages have been calculated using n, the number of valid (not missing or unknown) counts for each item. Missing or unknown values have not been imputed. 


\section{Results}

\section{Patient Demographics}

Out of the 85,126 patients in the database (2012-2016), 28,285 fulfilled the criteria of a pure or potential migraine population. The remaining patients either did not have data pertaining to all years from 20122016 or did not fulfill the criteria for the migraine population (Figure 2a). The mean age of migraine patients in the index year 2016 was 42.0 years and 33.7 years using the prevalence and incidence approach, respectively (Figure 2 b, c). The proportion of female migraine patients was $80.8 \%$ (prevalence approach) and $71.5 \%$ (incidence approach). On stratifying the patient population according to minors (aged 0-17 years), adults (aged 18-65 years) and elderly (aged $\geq 66$ years), it was observed that migraine was most prevalent in the adult age group of 18-65 years and least prevalent in the elderly. This was true for both the prevalence ( $84 \%$ vs $7 \%$ ) and incidence approaches ( $77 \%$ vs $3 \%$ ).

\section{Primary Endpoint}

The migraine prevalence rate in the Czech Republic remained stable during the period of 2012-2016. Only $1 \%(n=14,030)$ of patients from the total insured population $(n=1,288,409)$ had claims made towards migraine-related healthcare expenses in 2016. The migraine diagnosis rate among newly diagnosed patients, i.e. incidence approach patients, across $2012-2016$ was $0.2 \%-0.4 \%$. Hence, approximately one-third of the total migraine population was represented by newly diagnosed patients (Table 1).

\begin{tabular}{|lllllll|}
\hline $\begin{array}{l}\text { Index } \\
\text { year }\end{array}$ & \multicolumn{3}{l}{ Prevalence approach } & \multicolumn{4}{c|}{ Incidence approach } \\
\cline { 2 - 5 } & $\begin{array}{l}\text { Average size } \\
\text { of insured } \\
\text { population }\end{array}$ & $\begin{array}{l}\text { Number of } \\
\text { migraine } \\
\text { patients }\end{array}$ & $\begin{array}{l}\text { Migraine } \\
\text { prevalence } \\
\text { rate (\%) }\end{array}$ & $\begin{array}{l}\text { Average size } \\
\text { of insured } \\
\text { population }\end{array}$ & $\begin{array}{l}\text { Number of } \\
\text { migraine } \\
\text { patients }\end{array}$ & $\begin{array}{l}\text { Migraine } \\
\text { diagnosis } \\
\text { rate (\%)* }\end{array}$ \\
\hline 2012 & 1186766 & 12233 & 1.03 & 1186766 & 4379 & 0.37 \\
\hline 2013 & 1205627 & 12384 & 1.03 & 1205627 & 3564 & 0.30 \\
\hline 2014 & 1239890 & 13158 & 1.06 & 1239890 & 3623 & 0.29 \\
\hline 2015 & 1260834 & 13528 & 1.07 & 1260834 & 3297 & 0.26 \\
\hline 2016 & 1288409 & 14030 & 1.09 & 1288409 & 3049 & 0.24 \\
\hline $\begin{array}{l}\text { Migraine prevalence/diagnosis rate calculated as the percentage of migraine patients out of the } \\
\text { average insured population size covered by the Ministry of the Interior } \\
\text { Health Insurance Fund healthcare insurance company }\end{array}$ & & & \\
* The diagnosis rate decreases from 2012 to 2016 as for the reference year 2012, years covered were \\
2010-2011 whereas for the reference year 2016, years covered were 2010-2015
\end{tabular}

Table 1 
Migraine prevalence and diagnosis rate in the population covered by government-paid healthcare

\section{Secondary Endpoints}

\section{Prophylactic treatment}

Various antiepileptic and antidepressant drugs were prescribed to the migraine patients. Among the antiepileptic drugs, topiramate was predominantly used as a preventive treatment. Beta blockers were the only form of antihypertensive prescribed. For assessment of prophylactic treatment, cumulative medication lines $(0, \geq 1, \geq 2, \geq 3$ and $\geq 4)$ were considered.

\section{Number of migraine patients treated with a particular number of prophylactic medications}

The number of cumulative prophylactic lines assessed for the index year 2016 was 0 to $\geq 4$. Upon stratifying by age and using the prevalence approach for analysis, the mean age of migraine patients ranged between 48 and 53 years of age (three- and seven-year recall periods) for the $\geq 1$ to $\geq 4$ prophylactic lines (Table $2 \mathrm{a}$ ). The proportion of patients treated with $\geq 1$ prophylactic medication was $38.8 \%$ (three-year recall period) and $46.8 \%$ (seven-year recall period) (Table $2 \mathbf{b}$ ). The proportion of patients treated with $\geq 2$ prophylactic medications was $11.2 \%$ ( $84.6 \%$ females; three-year recall period) and $19.8 \%$ (86\% females; seven-year recall period) (Table 2 a, b). 
a) Descriptive patient characteristics (age and sex) by cumulative prophylactic line (prevalence approach)

All age groups; $\mathrm{N}=14030$

Prophylactic line*

Age (years)

Females

3-year recall

7-year recall

3-year recall

7-year recall

(2014-2016)

(2010-2016)

(2014-2016)

(2010-2016)

Mean (SD)

Mean (SD)

$\%$

$\%$

0

37.8 (15.6)

36.7 (15.7)

79.1

77.8

$\geq 1$

48.5 (14.6)

48.0 (14.4)

83.5

84.2

$\geq 2$

50.6 (13.2)

50.0 (13.4)

84.6

86.0

$\geq 3$

51.7 (12.5)

51.6 (12.6)

84.4

86.6

$\geq 4$

53.1 (12.6)

51.9 (11.7)

89.0

87.6

b) Number of migraine patients by cumulative prophylactic line (prevalence approach)

\begin{tabular}{|c|c|c|c|c|}
\hline \multirow[t]{3}{*}{ Prophylactic line* } & \multicolumn{2}{|l|}{$\begin{array}{l}\text { All age groups } \\
(\mathrm{N}=14030)\end{array}$} & \multicolumn{2}{|c|}{$\begin{array}{l}\text { Age group }>18 \text { years } \\
(N=12780)\end{array}$} \\
\hline & $\begin{array}{l}\text { 3-year recall } \\
\text { (2014-2016) }\end{array}$ & $\begin{array}{l}\text { 7-year recall } \\
(2010-2016)\end{array}$ & $\begin{array}{l}\text { 3-year recall } \\
(2014-2016)\end{array}$ & $\begin{array}{l}\text { 7-year recall } \\
(2010-2016)\end{array}$ \\
\hline & $n(\%)$ & $n(\%)$ & $n(\%)$ & $n(\%)$ \\
\hline 0 & $8584(61.2)$ & 7462 (53.2) & 7452 (58.3) & $6348(49.6)$ \\
\hline$\geq 1$ & $5446(38.8)$ & $6568(46.8)$ & $5336(41.7)$ & $6440(50.4)$ \\
\hline$\geq 2$ & $1567(11.2)$ & 2775 (19.8) & $1558(12.2)$ & $2756(21.6)$ \\
\hline$\geq 3$ & $417(3.0)$ & $1087(7.8)$ & 415 (3.2) & $1085(8.5)$ \\
\hline$\geq 4$ & $91(0.6)$ & $370(2.6)$ & $91(0.7)$ & $370(2.9)$ \\
\hline
\end{tabular}

c) Descriptive patient characteristics (age and sex) by cumulative prophylactic line; 3-year recall period (2014-2016) (incidence approach)

All age groups

$(\mathrm{N}=3049)$

Prophylactic line*

Age (years)

Mean (SD)

$32.7(16.1)$

\section{Females}

$\%$

70.6 


$\begin{array}{lll}\geq 1 & 40.1(14.2) & 77.4 \\ \geq 2 & 43.6(13.9) & 83.9 \\ \geq 3 & 44.2(12.8) & 91.7 \\ \geq 4 & 48(10.6) & 66.7\end{array}$

d) Number of migraine patients by cumulative prophylactic line; 3-year recall period (2014-2016) (incidence approach)

\begin{tabular}{llc} 
Prophylactic line* $^{*}$ & $\begin{array}{l}\text { All age groups } \\
(\mathrm{N}=\mathbf{3 0 4 9 )}\end{array}$ & $\%$ \\
\cline { 2 - 3 } & $n$ & 86.9 \\
0 & 2651 & 13.1 \\
$\geq 1$ & 398 & 1.8 \\
$\geq 2$ & 56 & 0.4 \\
$\geq 3$ & 12 & 0.1
\end{tabular}

${ }^{*}$ Cumulative prophylactic line: 0 , no prophylactic medication substances used; $\geq 1$, first and subsequent prophylactic line; $\geq 2$, second and subsequent prophylactic line; $\geq 3$, third and subsequent prophylactic line; $\geq 4$, fourth and subsequent prophylactic line. $\mathrm{n}$, umber of migraine patients by cumulative prophylactic line; $\mathrm{N}$, total number of migraine patients; $\%$, percentage of migraine patients with cumulative prophylactic lines out of the overall number of migraine patients with respect to the analysis approach and by the analysis population; SD, standard deviation

e) Proportion of migraine patients using prophylactic medication by therapeutic subgroup; 3-year recall period

\section{Therapeutic subgroup}

Antiepileptics other than topiramate

Beta blockers

Botulinum toxin $A^{*}$

Selected antidepressants

Topiramate

*Not reimbursable in the Czech Republic without special approvals; $n$, number of migraine patients in 2016 by therapeutic subgroup; $N$, total number of migraine patients in 2016; \%, percentage of migraine patients in the therapeutic subgroup out of the overall number of migraine patients in 2016 with respect to the analysis approach and by the analysis population
Prevalence approach

$(\mathrm{N}=14030)$

$n$

Incidence approach

$(\mathrm{N}=3049)$

$n \quad \%$

$173 \quad 5.7$

$106 \quad 3.5$

$4 \quad 0.1$

1015

7.2

66

2.2

1421

10.1

96

3.2 


\begin{tabular}{|c|c|c|c|c|}
\hline \multirow[t]{2}{*}{ Substance } & \multicolumn{2}{|l|}{$\begin{array}{l}\text { Prevalence approach } \\
(\mathrm{N}=14030)\end{array}$} & \multicolumn{2}{|c|}{$\begin{array}{l}\text { Incidence approach } \\
(\mathrm{N}=3049)\end{array}$} \\
\hline & $n$ & $\%$ & $n$ & $\%$ \\
\hline No medication & 8584 & 61.2 & 2651 & 86.9 \\
\hline Metoprolol & 1342 & 9.6 & 60 & 2.0 \\
\hline Atenolol & 138 & 0.9 & 5 & 0.2 \\
\hline Bisoprolol & 868 & 6.2 & 44 & 1.4 \\
\hline Candesartan & 115 & 0.8 & 6 & 0.2 \\
\hline Botulinum toxin $\mathrm{A}$ & 49 & 0.4 & 4 & 0.1 \\
\hline Valproic acid & 826 & 5.9 & 58 & 1.9 \\
\hline Topiramate & 1421 & 10.1 & 96 & 3.2 \\
\hline Gabapentin & 939 & 6.7 & 61 & 2.0 \\
\hline Pregabalin & 791 & 5.6 & 68 & 2.2 \\
\hline Amitriptyline & 341 & 2.4 & 28 & 0.9 \\
\hline Venlafaxine & 722 & 5.2 & 40 & 1.3 \\
\hline \multicolumn{5}{|c|}{$\begin{array}{l}\text { n, number of migraine patients with the corresponding prophylactic medication prescribed in } 2016 \text {; } N \\
\text { total number of migraine patients in } 2016 \text {; }\end{array}$} \\
\hline \multicolumn{5}{|c|}{$\begin{array}{l}\% \text {, percentage of migraine patients with the corresponding prophylactic medication out of the overall } \\
\text { number of migraine patients in } 2016 \text { with respect to the analysis approach and by the } \\
\text { analysis population }\end{array}$} \\
\hline
\end{tabular}

\section{Table 2}

Prophylactic treatment patterns for migraine patients

When selectively considering the adults, about $41.7 \%$ (three-year recall period) and $50.4 \%$ (seven-year recall period) of the population were using $\geq 1$ prophylactic medication (Table $\mathbf{2} \mathbf{b}$ ). At the same time, $12.2 \%$ (three-year recall period) and $21.6 \%$ (seven-year recall period) of the population were observed to be using $\geq 2$ prophylactic medications.

Among the newly diagnosed patients (patients analyzed by the incidence approach and by the three-year recall period), $86.9 \%$ of the population did not use any prophylactic medication. The mean age of patients ranged between 40 and 48 years of age for the $\geq 1$ to $\geq 4$ prophylactic lines, and $13.1 \%$ and $1.8 \%$ of the total patients were using $\geq 1$ and $\geq 2$ prophylactic medications, respectively. Approximately $84 \%$ of patients using $\geq 2$ prophylactic medications were females (Table $2 \mathrm{c}, \mathbf{d}$ ). 
The most prescribed therapeutic subgroups were antiepileptics (26\% with the prevalence approach [antiepileptics other than topiramate: $15.8 \%$, topiramate: $10.1 \%$ ] and $9 \%$ with the incidence approach [antiepileptics other than topiramate: $5.7 \%$, topiramate: $3.2 \%$ ]) and beta blockers (15.8\% for the prevalence approach and 3.5\% for the incidence approach) (Table $2 \mathrm{e}$ ). The most prescribed prophylactic medications using the prevalence approach were topiramate (10.1\%) and metoprolol (9.6\%), while newly diagnosed patients mostly used topiramate (3.2\%) and pregabalin (2.2\%), followed by metoprolol (2.0\%) (Table $2 \mathrm{f}$ ).

\section{Acute treatment}

Acute treatment comprised only of triptans, and 4299 patients $(30.6 \%, \mathrm{~N}=14,030$; prevalence approach) and 788 patients $(25.8 \%, \mathrm{~N}=3049$; incidence approach) who used triptans were not on a prophylactic drug therapy (Figure 3). For assessment of concomitant prophylactics, distinct/exact medication lines (1, 2, 3, and 4) were considered. With the incidence approach, we observed that patients using more than one prophylactic drug chose (or were prescribed) only sumatriptan. In the case of patients using only one prophylactic drug, of the 164 triptan therapy patients (incidence approach), 155 were using only sumatriptan. Similar observations were made using the prevalence approach, wherein 1487 among the 1677 patients on triptans with one prophylactic drug were on sumatriptan.

Overall, sumatriptan was being used by 6021 patients (approximately 43\%; prevalence approach) and 934 patients (30.6\%; incidence approach) (Figure 3). In the prevalence approach, the proportion of patients using triptans decreased with an increase in the number of simultaneous prophylactic drugs used.

\section{Number of migraine patients with comorbidities}

The insurance claims database did not register comorbidities for most migraine patients ( $98.6 \%$ by the prevalence approach and $99.2 \%$ by the incidence approach), and the comorbidities recorded were mostly cardiovascular disorders (1.34\%, prevalence approach; 0.91\%, incidence approach).

\section{Number of patients who could be eligible for CGRP therapy}

In the seven-year recall period, about $20 \%$ of patients (all age groups) and $21.6 \%$ of patients (adults only) used $\geq 2$ prophylactic therapies. Considering the number of inhabitants in the Czech Republic (10.7 million), the $1 \%$ migraine prevalence rate (with respect to insured healthcare) and the $21.6 \%$ patients on $\geq 2$ prophylactic medications, there could be up to 23,000 adult patients eligible for CGRP pathway-targeting therapies (Figure 4).

\section{Discussion}


There have been various studies across Europe and in other continents comparing the clinical and economic burden of migraine using various strategies as aforementioned [12, 14, 15]. The Burden of Episodic and Chronic Migraine in Europe (BECOME) study evaluated the burden of migraine across 17 European countries (including the Czech Republic) and Israel, but involved only tertiary healthcare centers [20].

Our study included data on primary and secondary healthcare on a national level, thus providing a broader overview of migraine management in the country. Most of the migraine patients were adults in their productive years and females, as observed in other studies [21-24]. Antiepileptics and beta blockers were observed to be the most commonly used prophylactic drugs. By prevalence approach, antiepileptics (topiramate) and beta blockers (metoprolol) were the most prescribed drugs, and the antiepileptics topiramate and pregabalin were mostly used by newly diagnosed patients. There is similar evidence supporting the use of beta blockers such as metoprolol [7,25], and antiepileptic drugs such as topiramate as preventive medication for migraine $[7,26]$.

Worldwide, treatment patterns vary because of reimbursement guidelines and requirements and differences in the prescribing patterns of healthcare practitioners. We observed that $13-39 \%$ of patients (depending upon prevalence or incidence approach) were on prophylactic medication with the three-year recall period, and when taking into account the seven-year recall period by the prevalence approach, the proportion of patients on prophylactic medication was about $47 \%$ (all age groups) and $50 \%$ (adults only). This clearly denotes that prophylactic therapy in the Czech Republic is underutilized. Additionally, in view of the European [27] and United States [4] recommendations for use of CGRP pathway-targeting therapies in patients with two prior prophylactic treatment failures, we deduced that 23,000 adult patients could be eligible for CGRP therapies.

\section{Strengths And Limitations}

Only $0.2-1 \%$ of the total insured population had migraine-related expenses towards general or government-paid healthcare. This maybe because majority of the migraine sufferers experienced mild migraine and used over-the-counter drugs such as general analgesics. Analgesics are mostly used against acute migraine and are not claimed because they cannot be reimbursed. This maybe also be a possible reason for our inability to capture acute treatment forms other than triptan therapy in the Czech Republic. Among the triptans, sumatriptan appeared to be the most trusted medication for acute treatment. Of note was the observation that $25-30 \%$ of the patients did not use any prophylactic drug along with triptan therapy (in both the prevalence and incidence approaches), and that triptan usage decreased in patients as the number of prophylactic drugs in use increased (prevalence approach). The latter observation agrees with one of the objectives of prophylactic treatment (to reduce the frequency of acute medication) and is in harmony with other studies $[6,7,28]$. Comorbidities were not well captured (only $1-2 \%$ of patients had recorded comorbidities) in this study since claims data does not describe every medical facet as customarily only the primary diagnosis is claimed. Moreover, if care is provided by general practitioners who are paid by capitation, the patients do not make health insurance claims since 
they will not be reimbursed. One unavoidable limitation in the study was the possible misidentification of newly diagnosed patients under the incidence approach. Many migraine patients do not feel the need to visit a physician or undergo any therapy until their symptoms aggravate. Consequently, relapsing patients (diagnosed before the index year) may have been included in the newly diagnosed patient population. Data obtained through the seven-year recall period provided a clear depiction of the number of long-term migraine sufferers, including those with prior treatment failures with more than two prophylactic drugs. This helps us understand the number of patients who are in need of CGRP therapy in the Czech Republic.

\section{Conclusion}

The findings of our observational study in the Czech Republic were similar to the worldwide trend; migraine has been managed with antiepileptics and beta blockers in the preventive setting and with triptans for acute therapy. Utilization of prophylactic therapy was associated with a decreased need for acute management of migraine as demonstrated by triptan use, which was higher in patients who were not on prophylactic treatment or were on a single prophylactic. There was a reduction in triptan use with combination prophylactics. About $50 \%$ of adult migraine patients were on preventive therapy and an estimated 23,000 individuals in the Czech Republic could be eligible for recent therapies using CGRP pathway antagonists such as erenumab. It will be worthwhile to observe the effects of such a drug on a national level to obtain a broader and more comprehensive understanding of its effectiveness as well as adoption as a standard in migraine management.

\section{Abbreviations}

DALY: Disability-adjusted life years; YLD: Years lived with disability; CM and EM: Chronic and episodic migraine; CGRP: calcitonin gene-related peptide; ZP MV: Ministry of the Interior Health Insurance Fund; BECOME: Burden of Episodic and Chronic Migraine in Europe

\section{Declarations}

\section{Acknowledgments}

The authors thank Shyamashree Dasgupta (Medical Communications, Novartis Healthcare Pvt. Ltd) for medical writing assistance in writing the manuscript, formatting, referencing, preparing tables and figures, incorporating the authors' revisions, and submission, all under the direction of the authors. The final responsibility for the content lies with the authors. All named authors comply with the International Committee of Medical Journal Editors (ICMJE) criteria for authorship of this manuscript. The authors thank ZPMV for providing the data for the analysis.

\section{Ethics approval and consent to participate}

See materials and methods 


\section{Consent for publication}

Not applicable

\section{Availability of data and materials}

The datasets of the current study are available from the corresponding author on reasonable request

\section{Competing interests}

DD did not receive any funding related to the development of this manuscript. JM has received consulting fees, speaking and/or teaching fees from Almirall, Amgen, Novartis and Teva, and study support from PROGRES Q35/LF3. DD has received consulting fees, and speaking and/or teaching fees from Allergan, Amgen, Biogen Idec, Novartis, Bayer, and Teva. JK, FD and ZP are Novartis employees. RS and AS were funded by Novartis for the statistical analyses.

\section{Funding}

The study was funded by Novartis, s.r.o. Erenumab is co-developed by Novartis and Amgen, and Novartis provided medical writing support for the preparation of this manuscript.

\section{Authors' contributions}

$\mathrm{DD}, \mathrm{JM}, \mathrm{JK}, \mathrm{ZP}, \mathrm{FD}$ and AS: study concept, design, data interpretation and critical revision of the manuscript. DD, JK, ZP, FD and AS: study supervision. JK, ZP and FD: obtaining study funding. RS: data interpretation, all statistical analyses and critical revision of the manuscript. AS: all statistical analyses. All authors contributed to the drafting of the manuscript and approved the final manuscript.

\section{References}

1. GBD Neurology Collaborators. Global, regional, and national burden of neurological disorders, 19902016: a systematic analysis for the Global Burden of Disease Study 2016. Lancet Neurol. 2019;18(5):459-80.

2. GBD Headache Collaborators. Global, regional, and national burden of migraine and tension-type headache, 1990-2016: a systematic analysis for the Global Burden of Disease Study 2016. Lancet Neurol. 2018;17(11):954-76.

3. Reuter U. GBD 2016: Still no improvement in the burden of migraine. The Lancet Neurology. 2018;17(11):929-30. 
4. American Headache Society. The American Headache Society Position Statement On Integrating New Migraine Treatments Into Clinical Practice. Headache. 2019;59(1):1-18.

5. Vargas BB. Acute Treatment of Migraine. Continuum (Minneap Minn). 2018;24(4, Headache):103251.

6. Schwedt TJ. Preventive Therapy of Migraine. Continuum (Minneap Minn). 2018;24(4, Headache):1052-65.

7. Silberstein SD. Preventive Migraine Treatment. Continuum (Minneap Minn). 2015;21(4 Headache):973-89.

8. Edvinsson L. Role of CGRP in Migraine. Handb Exp Pharmacol. 2019;255:121-30.

9. Lattanzi S, Brigo F, Trinka E, Vernieri F, Corradetti T, Dobran M, et al. Erenumab for Preventive Treatment of Migraine: A Systematic Review and Meta-Analysis of Efficacy and Safety. Drugs. 2019;79(4):417-31.

10. Han L, Liu Y, Xiong H, Hong P. CGRP monoclonal antibody for preventive treatment of chronic migraine: An update of meta-analysis. Brain Behav. 2019;9(2):e01215.

11. Wang SJ, Chen PK, Fuh JL. Comorbidities of migraine. Front Neurol. 2010;1:16.

12. Bloudek LM, Stokes M, Buse DC, Wilcox TK, Lipton RB, Goadsby PJ, et al. Cost of healthcare for patients with migraine in five European countries: results from the International Burden of Migraine Study (IBMS). J Headache Pain. 2012;13(5):361-78.

13. Linde M, Gustavsson A, Stovner LJ, Steiner TJ, Barre J, Katsarava Z, et al. The cost of headache disorders in Europe: the Eurolight project. Eur J Neurol. 2012;19(5):703-11.

14. Martelletti P, Schwedt TJ, Lanteri-Minet M, Quintana R, Carboni V, Diener HC, et al. My Migraine Voice survey: a global study of disease burden among individuals with migraine for whom preventive treatments have failed. J Headache Pain. 2018;19(1):115.

15. Vo P, Paris N, Bilitou A, Valena T, Fang J, Naujoks C, et al. Burden of Migraine in Europe Using SelfReported Digital Diary Data from the Migraine Buddy(c) Application. Neurol Ther. 2018;7(2):321-32.

16. Wu C-S, Lai M-S, Gau SS-F, Wang S-C, Tsai H-J. Concordance between patient self-reports and claims data on clinical diagnoses, medication use, and health system utilization in Taiwan. PLoS One. 2014;9(12):e112257.

17. Neubauer S, Kreis K, Klora M, Zeidler J. Access, use, and challenges of claims data analyses in Germany. The European journal of health economics : HEPAC : health economics in prevention and care. 2017;18(5):533-6.

18. Pavlovic JM, Yu JS, Silberstein SD, Reed ML, Kawahara SH, Cowan RP, et al. Development of a claims-based algorithm to identify potentially undiagnosed chronic migraine patients. Cephalalgia. 2019;39(4):465-76.

19. Czech Statistical Office. Public database CZSO 2019. Accessed on 2019-12-10. Available from: https://www.czso.cz/csu/czso/population. 
20. Lucas C, Pozo Rosich P, Watson D, Gaul C, Ramsden E, Ritter S, Martelletti P, Snellman J. A real-world analysis of the burden of migraine in patients with prior treatment failures: Evidence from the become study. J Headache Pain. 2019;20(1):109.

21. Borsook D, Dodick DW. Taking the headache out of migraine. Neurol Clin Pract. 2015;5(4):317-25.

22. Sokolovic E, Riederer F, Szucs T, Agosti R, Sándor PS. Self-reported headache among the employees of a Swiss university hospital: prevalence, disability, current treatment, and economic impact. J Headache Pain. 2013;14(1):29.

23. World Health Organization. Headache disorders 2016. World Health Organization. Accessed on 30 Dec 2019. Available from: https://www.who.int/news-room/fact-sheets/detail/headache-disorders.

24. Vetvik KG, MacGregor EA. Sex differences in the epidemiology, clinical features, and pathophysiology of migraine. Lancet Neurol. 2017;16(1):76-87.

25. Jackson JL, Kuriyama A, Kuwatsuka Y, Nickoloff S, Storch D, Jackson W, et al. Beta-blockers for the prevention of headache in adults, a systematic review and meta-analysis. PLoS One. 2019;14(3):e0212785.

26. Linde M, Mulleners WM, Chronicle EP, McCrory DC. Topiramate for the prophylaxis of episodic migraine in adults. Cochrane Database Syst Rev. 2013(6):Cd010610.

27. Sacco S, Bendtsen L, Ashina M, Reuter U, Terwindt G, Mitsikostas D-D, et al. European headache federation guideline on the use of monoclonal antibodies acting on the calcitonin gene related peptide or its receptor for migraine prevention. The journal of headache and pain. 2019;20(1):6.

28. Smelt AF, Assendelft WJ, van Dijk CE, Blom JW. Triptan use after starting prophylactic migraine treatment: a retrospective cohort study in a primary care population. Cephalalgia. 2014;34(11):92732.

\section{Figures}



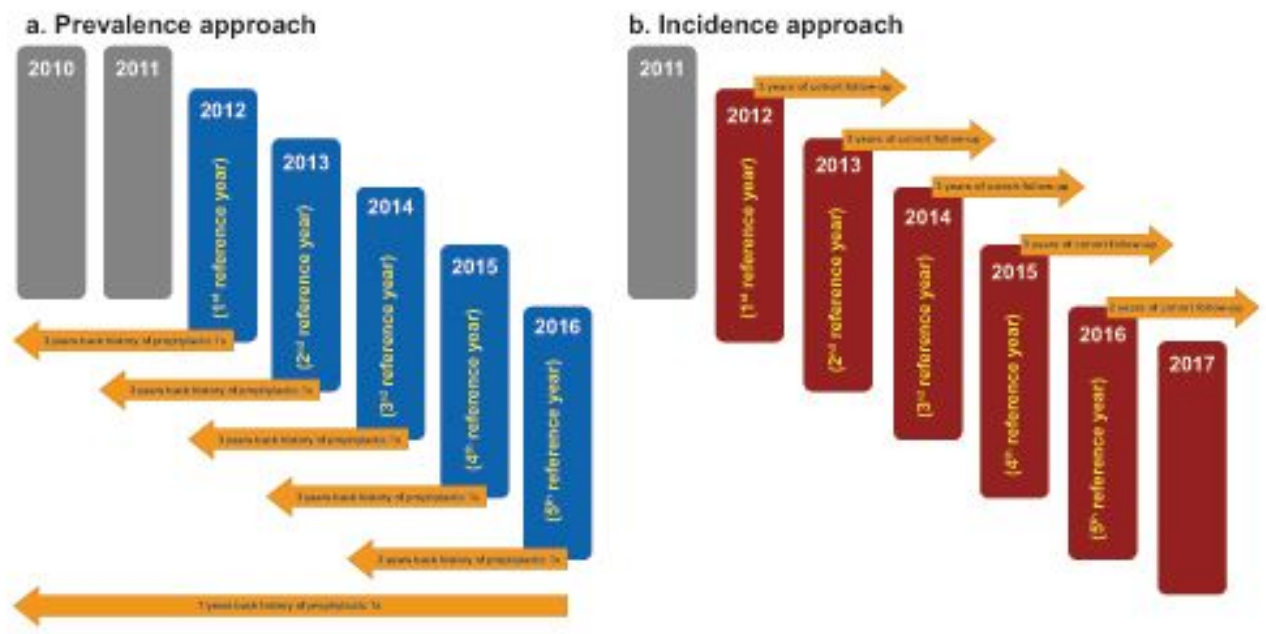

\section{Figure 1}

Study design for (a.) prevalence and (b.) incidence approaches. a. Prevalence approach (index years 2012-2016): Prophylactic therapies were followed up for three and seven years prior to the index year, including the index year, until 2010. b. Incidence approach (index years 2012-2016): Prophylactic therapies were followed up for the next three years, including the index year, until 2017. For the year 2016, therapies were followed for two years. Tx, treatments
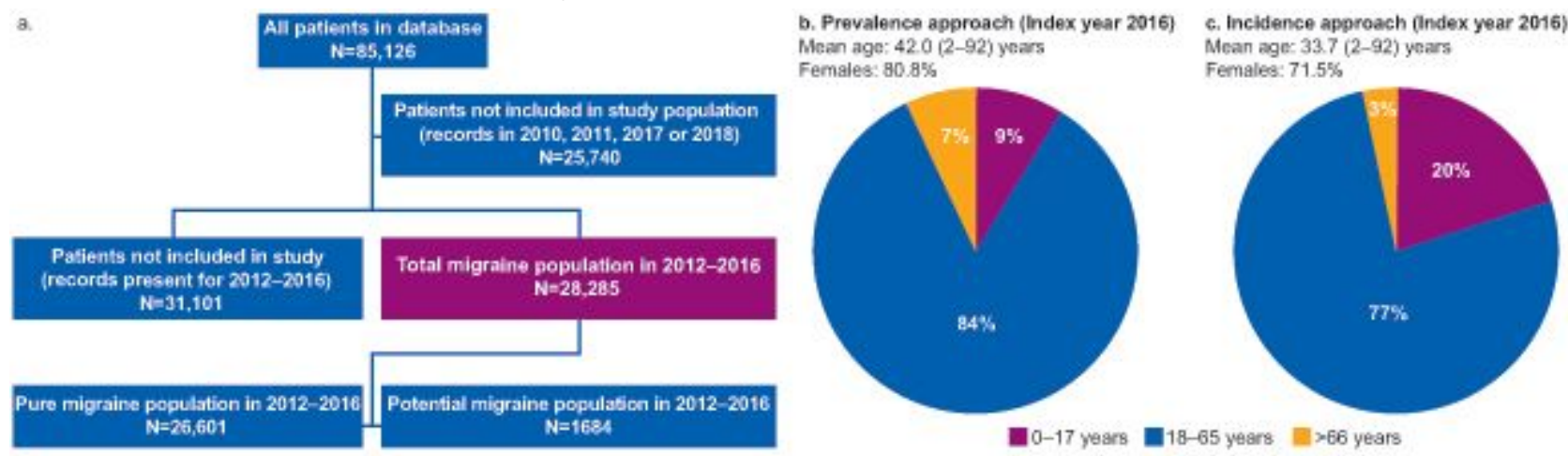

Figure 2

Study population and patient demographics 


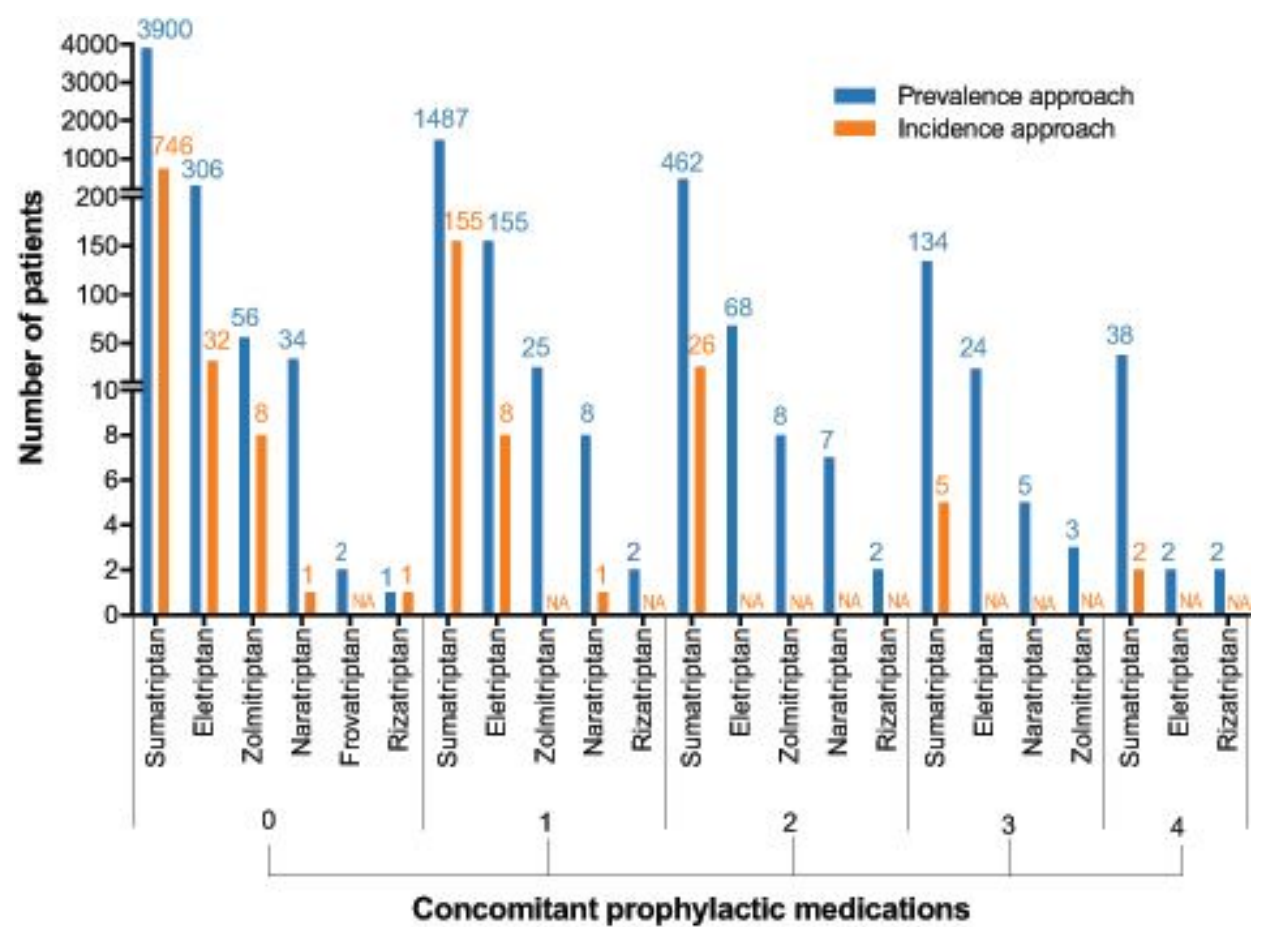

Figure 3

Number of migraine patients using triptans acutely while on prophylactic therapy in 2016 NA, not applicable

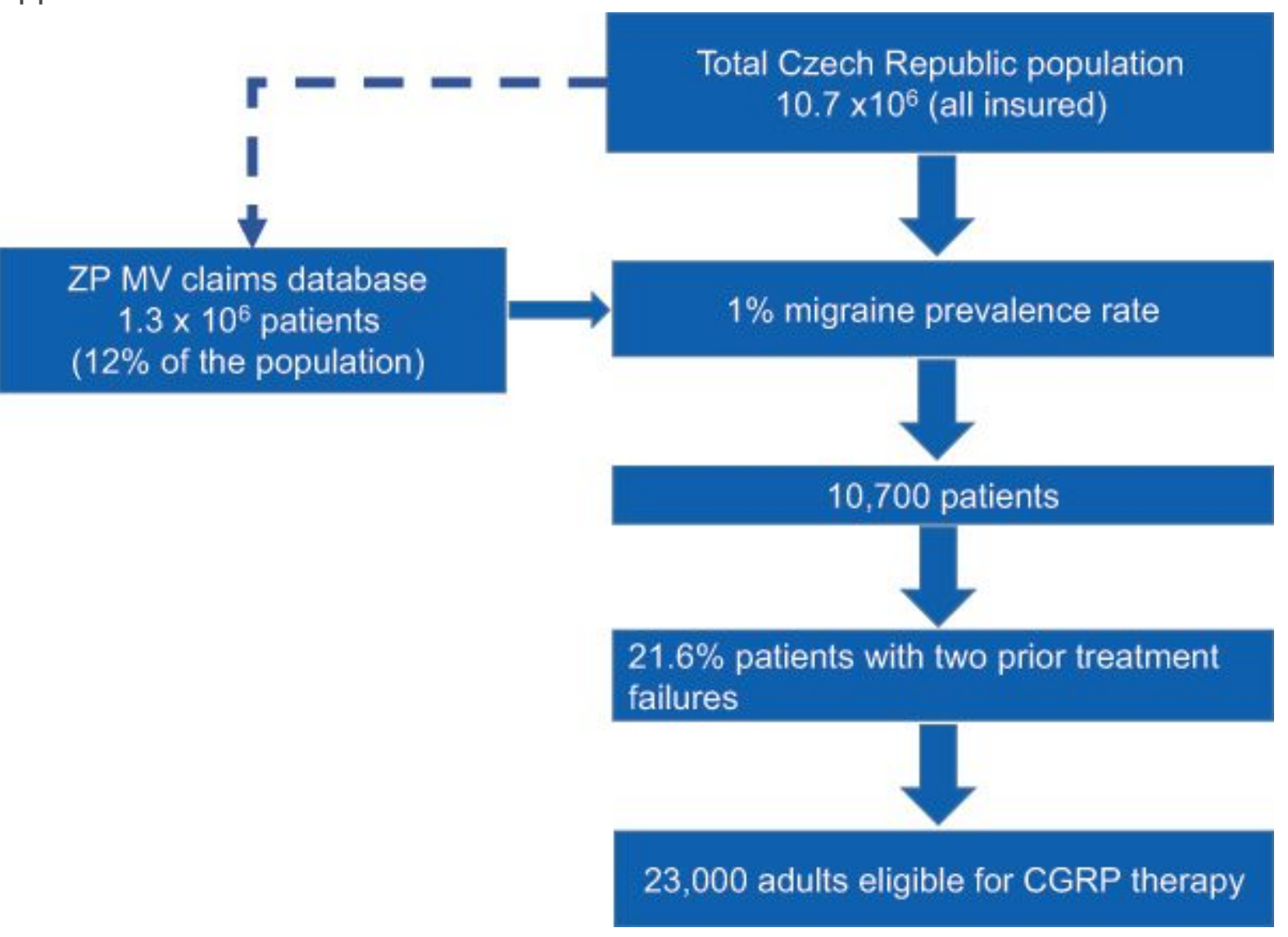

Figure 4 
Number of migraine patients who could be eligible for CGRP therapy in the Czech Republic CGRP, calcitonin gene-related peptide 